\title{
PARA PENSAR O DIGITAL: A LINGUAGEM EM FUNCIONAMENTO NO GOOGLE
}

\section{TO THINK DIGITAL: THE LANGUAGE IN OPERATION ON GOOGLE}

\author{
Daiana Oliveira Faria \\ Faculdade de Filosofia, Ciências e Letras de Ribeirão Preto \\ Universidade de São Paulo \\ daianafaria@pg.ffclrp.usp.br \\ Lucília Maria Sousa Romão \\ Faculdade de Filosofia, Ciências e Letras de Ribeirão Preto \\ Universidade de São Paulo \\ luciliamsr@uol.com.br
}

\begin{abstract}
RESUMO: Ancoramo-nos na Análise do Discurso de matriz francesa, sobretudo a partir dos trabalhos de Michel Pêcheux, para observar os efeitos de sentidos instalados pelo digital. Para tanto, tomamos como corpus trechos selecionados a partir de duas buscas realizadas no Google, sobre Dilma Rousseff e Marina Silva, considerando a forma de disposição dos resultados denominada Roda Mágica. Elegemos esses dois sujeitos, Dilma e Marina, a fim de observar o modo como eles foram discursivizados na rede no período de campanha eleitoral, em 2010, observando como atualizaram redes de memória ou instauraram sentidos outros.
\end{abstract}

Palavras-chave: Discurso. Internet. Google.

ABSTRACT: We anchor ourselves in the Discourse Analysis of the French headquarters, especially from the studies by Michel Pêcheux to observe the effects of the installed digital senses. For that, taken as a corpus of excerpts from two searches conducted on Google about Dilma Rousseff and Marina Silva, considering the form of disposition of results known as Magic Wheel. We chose these two subjects, Dilma and Marina, to observe how the effects produced on the network senses in the election campaign in 2010, observing how upgraded memory networks or introduce other senses.

Keywords: Discourse, Internet, Google.

\section{Discurso e rede eletrônica}

Partimos de um dos pressupostos centrais da teoria do discurso proposta por Michel Pêcheux: abordar a linguagem enquanto dado transparente, neutro e

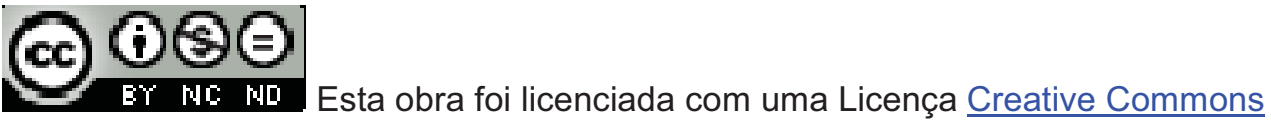

Texto Digital, Florianópolis, v. 7, n. 2, jul./dez. 2011. ISSNe: 1807-9288 
exato é uma ilusão. É justamente essa ilusão que é posta em xeque na base da Análise do Discurso francesa. "[...] Historicamente, esta problemática se formou (naquilo que concerne à França) em torno da questão da ideologia, e em particular da questão da leitura dos discursos ideológicos" (PÊCHEUX, 2011, p. 276). Tal problemática representava uma questão polêmica para a época, década de 50 e 60, na medida em que as vertentes teóricas dominantes se condensavam diante das formas do estruturalismo. E para corroborar a idéia de que o empirismo-lógico da linguagem é uma ilusão, Pêcheux (2011, p. 277) retoma Althusser:

\begin{abstract}
É desde Freud, escrevia Louis Althusser no início de Ler O capital, que nós começamos a suspeitar o que escutar, portanto falar (e se calar) quer dizer; que o "quer dizer" do falar e do escutar descobre, sob a inocência da fala e da escuta, a profundidade assinalável de um duplo-fundo, o "quer dizer" do discurso do inconsciente - este duplo fundo que a linguística moderna, nos mecanismos da linguagem, pensa os efeitos e condições formais (ALTHUSSER, 1968, p.14-15 apud PÊCHEUX, 2011, p. 277).
\end{abstract}

E como pensarmos o funcionamento da linguagem na contemporaneidade? A fim de refletirmos em torno disso, da materialidade discursiva do digital, recorremos ao escrito de Cristiane Dias, "Da corpografia: ensaio sobre a língua/escrita na materialidade digital" (2008), no qual a autora traça uma discussão teórico-analítica que fundamenta as discursividades instaladas pela Internet, principalmente, mas também pelas TIC's em geral. Dias apresenta reflexões em torno dos deslocamentos de paradigmas, em termos de língua e de escritura, proporcionados pelo uso do computador e pelas materialidades digitais em geral. A respeito deste deslocamento de paradigma, ela faz uma importante colocação, dizendo que

O que não se leva em consideração, entretanto, quando se pensa a grafia do internetês é o modo de funcionamento da língua no espaço discursivo da Internet, que tem a ver com a velocidade, com a linguagem de programação, que se constitui a partir de tecnologias numéricas e que por isso se diferencia radicalmente das técnicas da escrita tradicional, alfabética. Assim como nas condições de produção da escrita na época do papiro a "tecnologia da escrita" era outra, com sua 
temporalidade própria e suas condições de produção específicas (DIAS, 2008, p. 27).

Ou seja, estamos diante de condições de produção outras e, como diria Orlandi,

Essa conjuntura se apóia na tensa contradição entre, de um lado, a expectativa de uma democracia planetária ilusória e, de outro, a prática de uma real economia ditatorial. O "político" aparece nessa conjuntura como argumento. De forma importante, ligado a este discurso da mundialização, da globalização, há também um discurso sobre a subjetividade (ORLANDI, 2011, p.3)

E como falarmos em subjetividade na era das redes? Para buscar respostas para tal questão, inferimos que uma manifestação simbólica se dá sempre a conhecer na ordem do real, ou seja, na ordem do impossível. Ainda segundo Dias, esse modo outro de grafia se erige a partir do real da língua, do real da história e, ainda, do real do corpo, momento no qual a autora fala de "corpografia". Assim, estamos diante de

uma manifestação cultural da língua inserida numa discursividade que é a da tecnologia. Sendo assim, obviamente que concebida fora dessa cultura do teclar, da cultura digital, essa escrita não encontra ancoragem nos meios onde impera a 'paranóia institucionalizada' (PÊCHEUX e GADET, 2004). (DIAS, 2008, p. 18).

A autora acima mencionada encontra em Deleuze (1988) um aparato teórico que vai na direção de completar o que, na $A D$, chamamos de real, o real da língua, o real da história. Nesse caso, o real do corpo também. O conceito de simulacro entra nessa teorização como aquilo que transborda, que vai além do representável, que ultrapassa a ordem do possível na representação e que diz respeito a "uma resistência à língua fechada em uma estrutura, que a faz transbordar, dando assim lugar ao simulacro da língua" (DIAS, 2008, p. 32). Cabe aqui também a definição do conceito de simulacro nas palavras próprias de Deleuze: "sistema em que o diferente se refere ao diferente por meio da própria diferença" (DELEUZE, op.cit., p. 437). 
E é em torno destes questionamentos, que mais apontam questões outras do que encontram respostas, que traçamos nossas análises, buscando observar os efeitos de sentidos da materialidade digital. Com base nessas reflexões e no seu imbricamento com os postulados da $A D$, traçaremos nosso percurso de análise a seguir. Pretendemos corroborar com a hipótese de que a teoria de Análise do Discurso de matriz francesa encontra, na contemporaneidade, um cenário áureo para rever e trabalhar com seus postulados.

Para tanto, propomos, ao cabo dessas discussões teóricas, um exercício de análise que intenta vislumbrar na materialidade digital, a partir do site de pesquisa Google, os pressupostos pêcheuxtianos, flagrando o jogo de sentidos sobre a mulher no cenário atual da política brasileira. Temos, assim, traçado o recorte do campo discursivo que servirá de base para nossa análise.

\section{A linguagem em funcionamento no Google}

Propomos a escuta do funcionamento da linguagem em uma das ferramentas da busca Google denominada "Roda Mágica", lançada em maio de 2010 e que, depois de reformulado o layout da página, não se encontra mais disponível. $\mathrm{A}$ função desta ferramenta consiste em auxiliar o internauta a descobrir termos mais específicos relacionados àquilo que ele deseja encontrar. Vejamos como tal ferramenta é definida por seus idealizadores:

Roda mágica: esta opção apresenta conexões visuais entre as pesquisas relacionadas e seu termo de pesquisa como um diagrama interativo. Clique nos diferentes nós no diagrama para ver como as pesquisas podem se ramificar (GOOGLE, 2011, p. 2).

Ainda com base nas definições de seus idealizadores, podemos ver a linguagem em funcionamento, que é mais do que "evidências empírico-lógicas" (PÊCHUEX, 2011, p. 281), no mecanismo de busca Google. 
Se você não tiver certeza dos termos exatos que devem ser usados na sua pesquisa, comece por um termo de pesquisa mais abrangente e, em seguida, utilize essas ferramentas para descobrir termos alternativos (GOOGLE, 2011, p. 2).

Podemos observar nos trechos destacados que algumas características inerentes à linguagem já foram contempladas com esse recurso, mesmo que de modo a contê-las. No trecho "Se você não tiver certeza dos termos exatos", vemos que, pensando no jogo das formações imaginárias (PÊCHEUX, 1969 apud FARIA e ROMÃO, 2010, p. 54), o mecanismo de busca passa a ocupar uma posição no discurso, ou seja, representa um sujeito tal como postula a $A D$ e, a partir de sua posição, antecipa a posição de seu interlocutor, e infere que este, no nível discursivo, representará um sujeito incerto daquilo que deseja, o que é uma característica própria de ser/estar sujeito do discurso. Ora, sabemos que toda certeza e exatidão são postas em xeque quando, de fato, a linguagem funciona e falha, desliza. Apesar de se considerar essa possibilidade - a incerteza do sujeito interlocutor - pressupõe-se que isso pode ser contido, cercado e resolvido com a ferramenta em questão, o que é uma ilusão, pois

os sentidos não são indiferentes à matéria significante, a relação do homem com os sentidos se exerce em diferentes materialidades, em processos de significação diversos: pintura, imagem, música, escultura, escrita, etc. A matéria significante e/ ou sua percepção - afeta o gesto de interpretação, dá uma forma a ele (ORLANDI, 1998, p. 12).

Essa ilusão da possibilidade de conter os sentidos se daria da seguinte forma: "comece por um termo de pesquisa mais abrangente e, em seguida, utilize essas ferramentas para descobrir termos alternativos". Nessa sequência discursiva, inferimos ser atualizadas redes de memória discursiva sobre o poder e a potência da tecnologia, ou seja, um fio do discurso que permeia as palavras e as carrega de memória. Sabemos que as palavras se inscrevem no âmbito da história e, assim, carregam consigo memória discursiva, ou seja, a historicidade dos dizeres é atuante no discurso.

A questão da historicidade é uma questão presente na análise de discurso de maneira constante. Desse modo, quando 
falamos em sujeito, já está posta a relação língua/sujeito/história. E, quando falamos em sociedade, estamos pensando a sociedade tomada na história (ORLANDI, 2011, p. 1).

Para propor um termo de pesquisa mais abrangente, o sujeito precisa ter um mínimo acesso ao arquivo discursivo sobre a questão em busca. Elegendo este termo, o sujeito põe em cena o funcionamento da memória discursiva deste termo, que poderá ser observada nas formações discursivas (FD's) que o mecanismo de busca irá trazer, compreendendo FD enquanto regularidades entre enunciados, a partilha de sentidos em comum. A partir daí, é dada a possibilidade de percorrer por entre as FD's a fim de encontrar termos alternativos, ou seja, regiões de sentidos que, devido à historicidade dos dizeres e à memória discursiva, partilham de FD's que versam sobre aquilo que está sendo buscado pelo usuário. Anotamos, ainda, que tal ferramenta inscreve discursivamente o efeito de que a própria Roda Mágica poderia executar a busca completa para o sujeito navegador sem que ele mesmo precise saber sobre o tema. Enfim, uma verdadeira mágica de adivinhação que a tecnologia promete, atribuindo a si mesma o poder de executá-la.

Neste artigo, propomos a análise deste mecanismo a partir de duas buscas com os nomes Dilma Rousseff e Marina Silva, para flagrar o jogo de sentidos sobre a mulher na política no período de campanha eleitoral, em 2010. Sobre a materialidade da designação do nome próprio, sabemos que se trata de uma materialidade de confronto. "Assim, a relação de designação é uma relação instável entre a linguagem e o objeto, pois o cruzamento de discursos não é estável, é, ao contrário, exposto à diferença" (GUIMARÃES, 1995, p. 74). No caso, essa diferença implica dois nomes de mulheres, duas posições partidárias, dois cargos políticos, uma pura diferença que desejamos escutar discursivamente. Este confronto pode ser observado com a linguagem em funcionamento no Google, a partir da busca feita sobre os nomes das candidatas à Presidência da República. Além deste confronto, inerente à linguagem, sabemos que outro aspecto constitutivo, como vimos, é a historicidade dos dizeres, atuante também no caso da nomeação, dado que as palavras da história são nomes, nomes que não designam classes de objetos 
apenas, mas que identificam: "um nome identifica, ele não classifica" (RANCIÉRE, 1992, p. 43 apud COSTA, 2004, p. 24).

Por estarmos diante de nomes próprios, é inevitável pensarmos nos indivíduos que eles representam, Dilma e Marina. Porém não é a estes que nos referimos, visto que nos interessam as posições-sujeito que se instalam a partir desses nomes de mulheres inscritos na política brasileira atual. Para não incorrermos nesse equívoco, (como veremos, ele é comum), cabe a distinção:

não é possível falar em sociedade sem pensar o indivíduo - ou o sujeito individualizado [...] - dado o fato de que, quando nos voltamos para a compreensão das questões sociais, a questão da sociedade é fortemente marcada pelo discurso da sociologia e esta erige esta noção como fundamental (ORLANDI, 2011, p. 1)

O que nos interessa é o que a noção de indivíduo deixa escapar, pois "o que fica de fora quando se pensa só o sujeito já individualizado, é justamente o simbólico, o histórico e a ideologia que torna possível a interpelação do indivíduo em sujeito" (ORLANDI, 2011, p. 107). Por isso, nossa escuta dirige-se ao que está em jogo no discurso quando posições sobre a mulher na política, na gestão pública, no executivo e na militância são colocadas em discurso. Isso posto, observemos a discursividade da busca sobre Dilma Rousseff e Marina Silva no Google em janeiro de 2011, a partir da ferramenta Roda Mágica (Fig. 1):

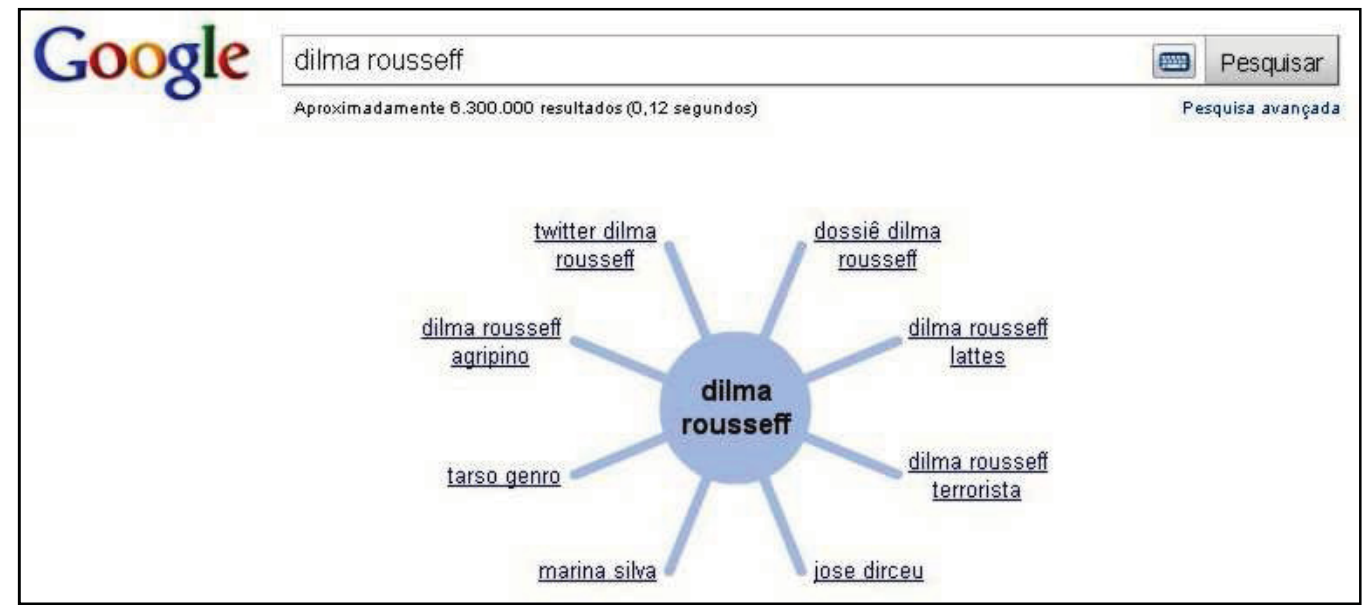






Figura 1: Buscas no Google utilizando a ferramenta Roda Mágica

Num primeiro momento, já podemos observar que, na busca por "Marina Silva", não vemos "Dilma Rousseff" como uma possível associação, ou seja, há uma exclusão explicitada pelo dispositivo da Roda Mágica, de maneira que tais modos circulariam em trilhas separadas na rede eletrônica. Tomados enquanto posição no discurso, outros sujeitos que não Dilma Rousseff foram inscritos São eles: Carlos Minc e Heloisa Helena. Sabemos que a linguagem está intrinsecamente relacionada com a história e que todo discurso se dá segundo suas condições de produção, ou seja, atravessado pelo contexto sóciohistórico-ideológico. A partir disso, anotamos que, neste momento da história 
do país, Dilma Rousseff já tinha sido eleita e Marina Silva não representava mais, por ora, uma concorrente. Nos termos do discurso, Dilma Rousseff, enquanto sujeito do/ao discurso, foi silenciada, mas ainda assim produziu sentidos. De acordo com Orlandi (1992), o silêncio indica que o sentido pode sempre ser outro.

Instigadas por esse silêncio, fizemos a busca por "Dilma Rousseff" e, então, o sujeito Marina Silva foi inscrito. Podemos inferir que um jogo entre FD's incitou a inscrição do sujeito Marina Silva partilhando das mesmas FD's que Dilma Rousseff e, num deslize entre sentidos porosos, não promoveu a inscrição do sujeito Dilma Rousseff partilhando as mesmas FD's de Marina Silva. O que parece um equívoco representa, de fato, uma característica da linguagem: ela falha e está sempre prestes a mancar e a equivocar-se. Com isso, vemos que um todo coeso, estruturado, não é possível, o que nos faz pensar que aquele esquema proposto por Jakobson (2005) não funciona de modo direto, unívoco e transparente, uma vez que tal autor propõe um canal em linha reta, no qual a ida e a volta da comunicação são garantidas com a mensagem sempre desvestida de ruídos.

Vimos acima que este esquema falhou. Onde era esperada a mesma mensagem, encontramos algo diferente; no lugar em que o previsível garantiria um caminho de ida e volta nos mesmos termos, algo irrompe como imprevisível. Até mesmo esse jogo de FD's foi furado quando a ferramenta Roda Mágica propôs a associação entre os sujeitos Dilma Rousseff e Marina Silva, pois tal associação não foi possível. Com isso, vemos um esforço do mecanismo de busca em manter o esquema da comunicação, apesar de propô-lo na forma de um diagrama radial, esforço este que deixou às vistas os furos inerentes ao funcionamento da linguagem.

Outro fato curioso é que, a partir destas condições de produção, o sujeito Chico Mendes, por exemplo, não apareceu partilhando das mesmas FD's de Marina Silva, o que foi recorrente em outro momento da história (FARIA; YADO e ROMÃO, 2011), e ainda o é hoje em vários outros discursos na própria rede eletrônica. O que nos mostra mais uma vez que a inscrição de sujeitos dá-se 
segundo suas condições de produção. Além disso, tal como ocorreu com o sujeito Dilma Rousseff, apesar de o sujeito Chico Mendes não ter sido inscrito, ele produziu sentidos, uma vez que os dizeres Marina Silva, carregados de historicidade, instalaram o trabalho da memória discursiva, mesmo que silenciando este sujeito, ressaltando que o silêncio é também (e talvez principalmente) uma forma de estar na linguagem. Um sujeito que tem acesso a este arquivo discursivo pode interpretar que Marina e Chico partilham das mesmas FD's e que suas vozes, de um modo ou de outro, atualizaram certas regiões de sentido sobre a luta dos seringueiros, a reivindicação de direitos e a preservação das reservas naturais amazônicas. Já um sujeito que simplesmente não tem acesso a esse arquivo, não teria promovido a inscrição do sujeito Chico Mendes, tampouco tecido e destecido relações de sentidos entre os links presentes e ausentes na Roda Mágica.

\section{Considerações finais}

Observamos que, mais do que representar um novo suporte de informação, a Internet representa um modo outro de ser/estar na linguagem, instalando outras condições de produção da linguagem em funcionamento. Assim, vemos que a produção de discursos na contemporaneidade tem se dado a partir desses deslocamentos de paradigmas, em termos de leitura e escrita. Deslocamentos estes que promovem outros modos de inscrição do sujeito e de produção dos sentidos e que implicam considerar a noção de movimento constante dos dispositivos e dos sujeitos, tomando-os na espessura do real. $E$ isso faz toda a diferença. Ao invés de olharmos para a tela, a tecnologia e as "ferramentas" da net como dotadas de completude e eficácia, é preciso que as leiamos à luz da noção de real na visada de que há um impossível sempre presente, algo que jamais poderá ser alcançado, recuperado e controlado. $O$ que Pêcheux nos deixou como o real da língua, da história e do sujeito são condições para pensarmos o que escapa como condição do discurso. 


\section{Referências}

COSTA, Fabiana Claudia Viana. Designação e referência uma análise enunciativa do Censo Demográfico 2000. 2004. 77 f. Dissertação (Mestrado) Departamento de Letras, Unicamp, Campinas, 2004. Disponível em: < http://www.bibliotecadigital.unicamp.br/document/?code=vtls000323166>.

Acesso em: 07 jun. 2011.

DIAS, Cristiane Pereira. Da corpografia: ensaio sobre a língua/escrita na materialidade digital. Santa Maria: UFSM, Programa de Pós-Graduação em Letras, 2008.

FARIA, Daiana Oliveira; ROMÃO, Lucília Maria Sousa. Google e o movimento de sentidos. Versão Beta: sob o signo da palavra, São Carlos, p. 41-60, 2010.

FERREIRA, Maria Cristina L. (Org.). Glossário de termos do discurso. Porto Alegre: $\quad$ UFRGS, 2001. Disponível em:< http://www.discurso.ufrgs.br/glossario.html>. Acesso em: 26 maio 2011.

GOOGLE (São Paulo). Ajuda do Pesquisa na web. Sobre a ferramenta Roda Mágica. Disponível em: < http://support.google.com/websearch/bin/answer.py?hl=pt-R\&answer=142143>. Acesso em: 07 jun. 2011.

JAKOBSON, Roman. Linguística e Comunicação. São Paulo: Cultrix, 2005.

ORLANDI, Eni P. As formas do silêncio. Campinas: Editora da Unicamp, 1992.

PÊCHEUX, Michel; HAROCHE, Claudine; HENRY, Paul. A semântica e o corte saussuriano: língua, linguagem e discurso. Linguasagem: Revista eletrônica de popularização científica em ciências da linguagem, São Carlos, n. 03, p. 01-19, out/nov. $2008 . \quad$ Disponível em: <http://www.letras.ufscar.br/linguasagem/edicao03/>. Acesso em: 26 maio 2011.

PÊCHEUX, Michel. Contextos epistemológicos da análise de discurso. Escritos: linguagem, cidade, política, sociedade, Campinas, n. 4, p. 07-16, maio 1999. Tradução de Eni Orlandi (Labeurb/Nudecri).

ZANDWAIS, Ana. Perspectivas da análise do discurso fundada por Michel Pêcheux na França: uma retomada de percurso. Santa Maria: UFSM, Programa de Pós-Graduação em Letras, 2009. 